\title{
Stall Inception in Low Pressure Ratio Fans
}

\author{
S. Kim; G. Pullan; C.A. Hall, R.P. Grewe \\ Whittle Laboratory \\ University of Cambridge \\ $1 \mathrm{JJ}$ Thomson Avenue \\ Cambridge, CB3 ODY, UK
}

\author{
M.J. Wilson \\ Rolls-Royce plc \\ Moor Lane \\ Derby, DE21 8BJ, UK
}

\author{
E. Gunn \\ Turbostream Ltd \\ 3 Charles Babbage Road \\ Cambridge, CB3 0GT, UK
}

\begin{abstract}
A combined experimental and computational test programme, with two low pressure ratio aero-engine fans, has been used to identify the flow mechanisms at stall inception and the subsequent stall cell growth. The two fans have the same rotor tip clearance, annulus design and downstream stators, but different levels of tip loading. The measurement data show that both fans stall via spike-type inception, but that the growth of the stall cell, and the final cell size, is different in each fan. The computations, reproducing both the qualitative and quantitative behaviour of the steady-state and transient measurements, are used to identify the flow mechanisms at the origin of stall inception. In one fan, spillage of tip leakage flow upstream of the leading edge plane is responsible. In the other, sudden growth of casing corner separation blockage leads to stall. These two mechanisms are in accord with the findings from core compressors. However, the transonic aerodynamics and low hub-to-tip radius ratio of the fans leads to the following two findings: first, the casing corner separation is driven by shock-boundary layer interaction; second, the spanwise loading distribution of the fan determines whether the spike develops into full-span or part-span stall and both types of behaviour are represented in the present work. Finally, the axial momentum flux of the tip clearance flow is shown to be a useful indicator of the leakage jet spillage mechanism. A simple model is provided that links the tip loading, stagger and solidity with the tip clearance axial momentum flux, thereby allowing the aerodynamicist to connect, qualitatively, design parameters with the stall behaviour of the fan.
\end{abstract}

\footnotetext{
${ }^{*}$ Present address: R\&D Center, Hanwha Aerospace, Republic of Korea

$\dagger$ Email: gp10006@cam.ac.uk

¥Present address: Siemens, Mülheim an der Ruhr, Germany
} 


\section{INTRODUCTION}

At low flow rates, the operation of an aero-engine fan is limited either by aerodynamic instability (rotating stall) or by aero-mechanic instability (flutter). At high speed, above the speed range influenced by the so-called 'flutter bite', rotating stall is typically dominant. Increases in propulsive efficiency are associated with a reduction in fan pressure ratio. In this work, fan pressure ratios of order 1.4 are considered low, as compared to the pressure ratio of conventional fans which is typically greater than 1.5 . As the fan pressure ratio is reduced, a given inlet distortion will cause a larger excursion in fan operating point and hence the designer seeks an accurate knowledge of the stability boundary and of the flow mechanisms that determine it.

In this paper, we use a combined computational and experimental approach to determine the aerodynamic mechanisms present at the inception of rotating stall in transonic fans. We show that, in accord with the behaviour of core compressors, tip leakage flow spillage upstream of the leading edge of the adjacent blade, and sudden growth of casing blockage, are the two triggers at the origin of stall inception. The transonic aerodynamics and low hub-to-tip radius ratio that characterise fans, however, mean that shock-boundary layer interaction is linked to the casing blockage growth and that the mature stall cell can be localised (part-span stall). Although the test cases used in, and motivation for, the present work are low pressure ratio fans, we consider these mechanisms to be generic in their applicability to aero-engine fans.

The paper is organised as follows. Previous findings on compressor and fan stall inception are reviewed in the next section. The two fan geometries, the experimental test rig and the computational approach are then described. The calibration of the computations with the steady experimental data is then discussed, followed by the use of unsteady computations in the interpretation of transient test rig data.

\section{STALL ONSET IN COMPRESSION SYSTEMS}

Two distinct routes to rotating stall have been identified [1]. In the first, small amplitude, long length-scale (of order machine circumference) perturbations in the circumferential distribution of velocity grow exponentially and evolve into a stall cell; this is the 'modal' route to rotating stall [2]. In the second, the disruption to the circumferential distribution of velocity is sudden, large amplitude and local (of order blade pitch); this is the 'spike' route to rotating stall [3]. The experimental data from the fans tested in the current work show that spike-type stall inception occurs and we focus on that route.

Computations in core compressors have identified the physical phenomena responsible for the spike (the sharp up-down wave-form recorded on a casing pressure transducer trace) and its origins [4]. The spike is formed by vorticity shed from the leading edge of the blade at high incidence. This incidence can arise either from the tip clearance flow of the adjacent blade or from corner separation blockage within the passage. Tip clearance, in particular the axial momentum of the tip clearance jet, is a determining factor in which of these two mechanisms dominates [5].

In contrast to the research cited in core compressors, fans are characterized by the role of shocks in the compression process and by low hub-to-tip radius ratios. Several authors have reported experimental and computational studies of both the behaviour of the shocks $[6,7]$ and also the flow structures associated with stall inception in fans [8-10]. At stall inception, forward spillage of the tip leakage flow upstream of the adjacent leading edge has been observed for transonic rotors in 
computations ranging from steady single passage [8] to full annulus large eddy simulation [9]. For a fan operating at two different speeds, quantitative agreement (stall cell number and stall cell rotational speed) has been obtained between unsteady Reynolds-averaged Navier-Stokes computations and fan test data [10].

In this paper, computations and experiments from two aero-engine fans with the same nominal design pressure ratio are reported. During the test programme, the fans exhibited different spike-type rotating stall behaviour, notably in stall cell growth rate and fully developed cell size. The computations, corroborated by the experimental data, demonstrate that different fluid mechanisms, spillage of the tip leakage flow and sudden growth of casing corner separation blockage, occur in each fan.

\section{FAN GEOMETRIES AND TEST PROGRAM}

Two fan geometries have been assessed, experimentally and computationally, in the present work, 'VITAL' and 'FAN A'. The VITAL fan has been used in several studies [11,12] and FAN A has also been previously reported [13]. Both fans operate with a similar overall pressure ratio (nominally 1.4) at the design point. VITAL has a design tip relative Mach number of 1.2, for FAN A the value is 1.1. Of particular relevance to the present study, the radial distribution of loading is also different between the two fans: in VITAL, the loading is markedly reduced over the outer $30 \%$ of span; for FAN A a more uniform profile is maintained.

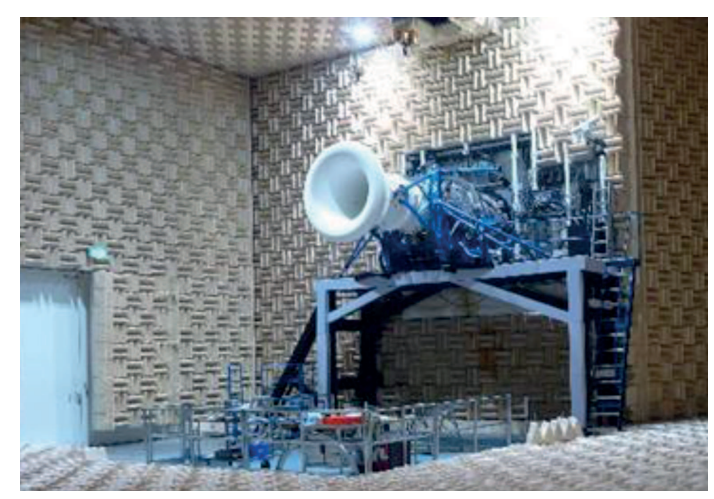

(a) AneCom AeroTest noise test facility

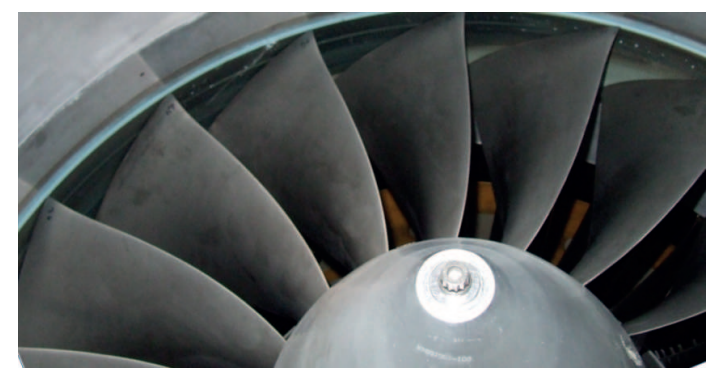

(b) The VitAl fan

Fig. 1: The fan test facility at AneCom AeroTest, Germany

Both fans have been tested, with downstream stators in the bypass and core streams, in the AneCom AeroTest facility, Germany, Fig. 1. The facility allows an approximately one-third scale the fan to operate at the correct Mach number. The tip Reynolds number for the VITAL fan was 4.1 million. Of interest here is the acquisition of steady-state and transient data. 
Three performance planes, at rotor inlet, outlet guide vane inlet and core stator inlet, were instrumented with total pressure and total temperature rakes. Six Kulite fast-response pressure transducers, distributed around the annulus, on the casing, at $54 \%$ of axial chord upstream of the VITAL leading edge, were used to record the development of rotating stall.

\section{COMPUTATIONAL APPROACH}

The computations were performed using Turbostream [14]. The code is a structured multi-block unsteady Reynoldsaveraged Navier-Stokes (U-RANS) solver and uses a finite-volume time marching approach (second order in space). Time integration to a steady-state is performed using a single-step explicit scheme; unsteady computations are second order accurate using Jameson's dual time stepping technique (160 physical time steps per fan blade passing period). Following the work of [13], all simulations in this paper were obtained using the helicity-based modification [15] to the standard SpalartAllmaras turbulence model with adaptive wall functions and fully turbulent boundary layers. Comparisons of results with the original and modified Spalart-Allmaras models are provided in the Appendix.

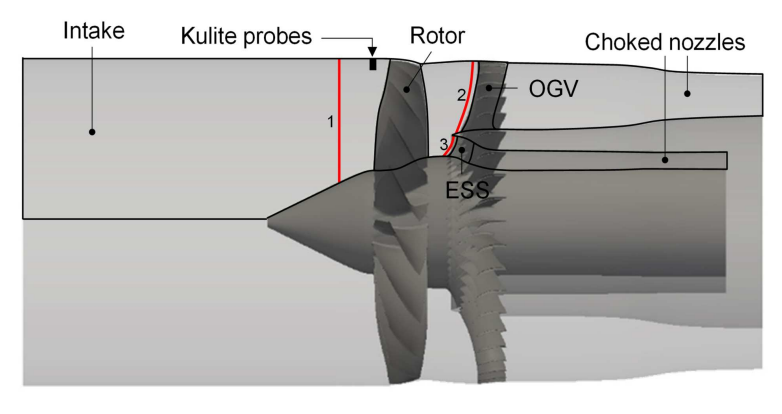

Fig. 2: Computational domain for fan simulations

The computational domain, Fig. 2, extends approximately one fan tip diameter upstream and downstream of the rotor. The stagnation pressure profile of the casing boundary layer at fan inlet is matched to experimental data from the tests. Convergent nozzles are used at the bypass and core outlets in order to aid convergence when the slope of the pressure rise versus mass flow characteristic approaches zero [16]. The mesh was generated using Autogrid from Numeca with of order 4 million points for the steady computations and 100 million points for the full annulus unsteady computations. The resultant grid had nominal y-plus values of 5 on the blade and endwall surfaces.

The following procedure was adopted for the unsteady computations of stall inception. To provide a non-uniformity in the rotor assembly, and hence a likely site for the emergence of a spike, one of the fan blades was restaggered by 0.2 degrees (in the direction to increase the incidence). The first unsteady computation is initialised from a converged steady solution at an operating point away from the 'stability boundary' of the steady computation. The area ratio of the bypass nozzle is closed in steps of $1 \%$ and then $0.5 \%$.

\section{STEADY-STATE RESULTS}

The objective of the steady computations is two-fold. First, comparisons with steady test data give confirmation that the un-stalled flow fields are captured with sufficient accuracy. Second, to provide an initial operating point for the unsteady 
computations of stall inception. The computational cost of the two types of simulation differs by two orders of magnitude.

For each fan, overall characteristics and exit flow profiles, at two operating points (both at $100 \%$ speed), are presented.

The pressure ratio and isentropic efficiency characteristics for VITAL, Fig. 3, illustrate close agreement between the steady computations and the measurement data between choke and a normalised mass flow of 0.87 . At mass flows below this region, the discrepancy in pressure ratio increases above 0.01 and in efficiency to more than $0.5 \%$. Figure 3 also indicates the operating point of the final stable unsteady computation before a further throttling of the fan initiated stall; this point is within 0.01 of normalized mass flow of the experimentally determined stability limit.
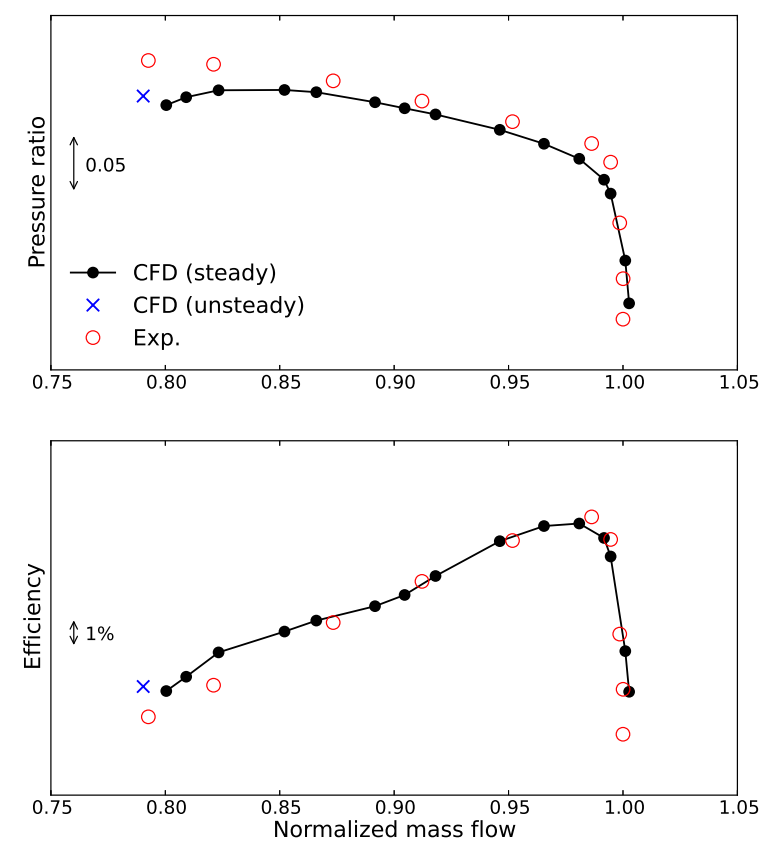

Fig. 3: Performance characteristics for VITAL, $100 \%$ speed

Radial profiles of pressure ratio, Fig. 4, at inlet to the bypass duct show that the zone outboard of $70 \%$ span is associated with deviation of the computation from the experiment at low flows. Surface streamlines, Fig. 5 reveal that the flow in this region is influenced by radial migration of the thickened suction-surface boundary layer downstream of the shock. It has been found that this radial flow, and hence the spanwise profiles outboard of $70 \%$ span, is sensitive to changes in turbulence modelling (see Appendix).

The experimental and computational characteristics for FAN A are shown in Fig. 6. The agreement in pressure ratio is within 0.02 throughout, but there is an over-prediction in efficiency of order $1 \%$. The final stable unsteady computation is, at 0.02 of normalized mass flow rate, further from the experimental stability limit than the steady computations; however, the throttle increments used are equivalent to the same order of mass flow reduction.

The radial profiles, Fig. 7, indicate that a consistent over-prediction of the pressure ratio, and under-prediction of the temperature ratio, in the outer half of the span leads to the offset in efficiency. In common with VITAL, the computations perform best in the inner portion of the fan where radial migration, and the associated skewed suction-surface boundary 

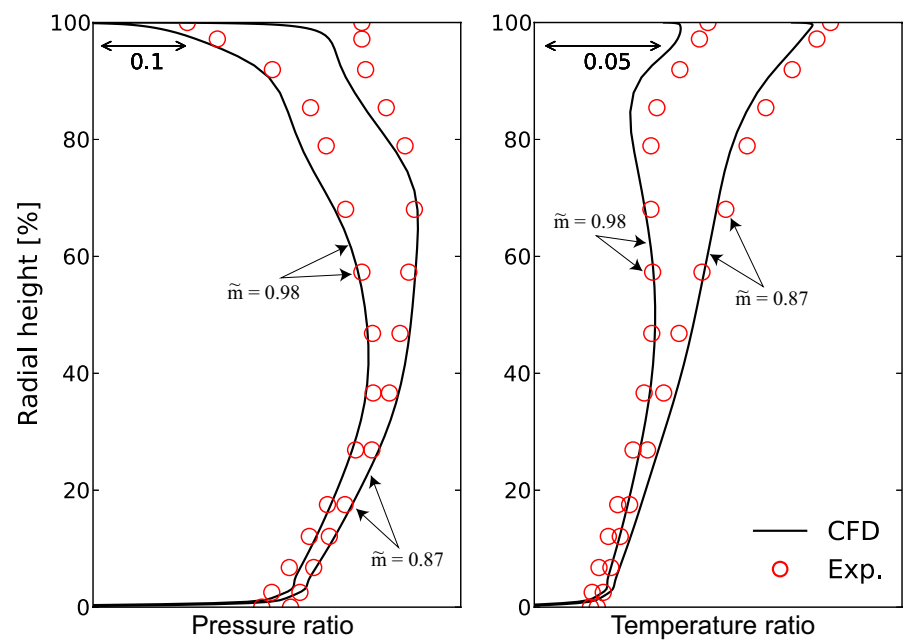

Fig. 4: Spanwise profiles for VITAL at inlet to the bypass duct, at peak efficiency and low flow rates

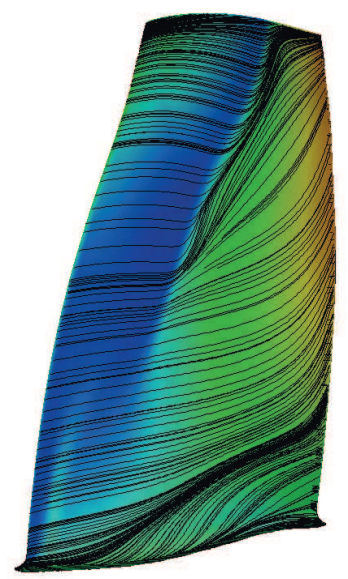

(a) Peak effciency

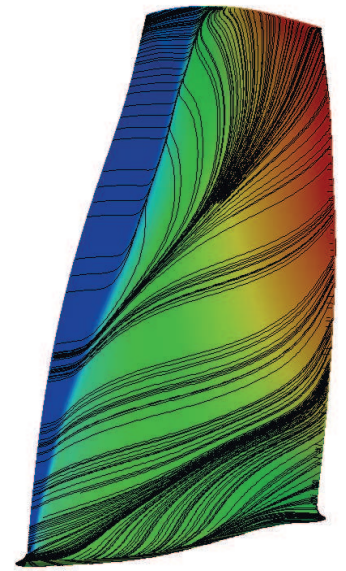

(b) Near stall

Fig. 5: Suction-surface limiting streamlines, VITAL

layer, plays a relatively minor role.

The conclusion we draw from the above comparisons is that the computations, across the operating points assessed, are in sufficient qualitative and quantitative agreement with the measurement data to provide a starting point for the transient analysis to come. The radial profiles of Figs. 4 and 7 also illustrate the primary difference in the design philosophies of the two fans. The pressure ratio profile is flatter for FAN A than VITAL: the tip loading of VITAL falls over the outer 30\% of span; for FAN A, pressure ratio is approximately constant from $30 \%$ to $90 \%$ span, before falling over the outer $10 \%$. We will show that this contrast in loading style is reflected in different stall inception mechanisms, and mature stall flow fields, for the two fans.

\section{CAPTURE OF STALL INCEPTION BEHAVIOUR}

Before the computations are used to identify the flow phenomena at stall inception, and the link to fan design, we first compare the simulated and measured casing pressure traces. As the fans were throttled on test, different stall inception behaviour was recorded. For VITAL, the transition to rotating stall was sudden, leading to a large full-span stall cell. For FAN A, stall was observed to be 'progressive', with part-span stall. In this section, we will show that this behaviour, as 

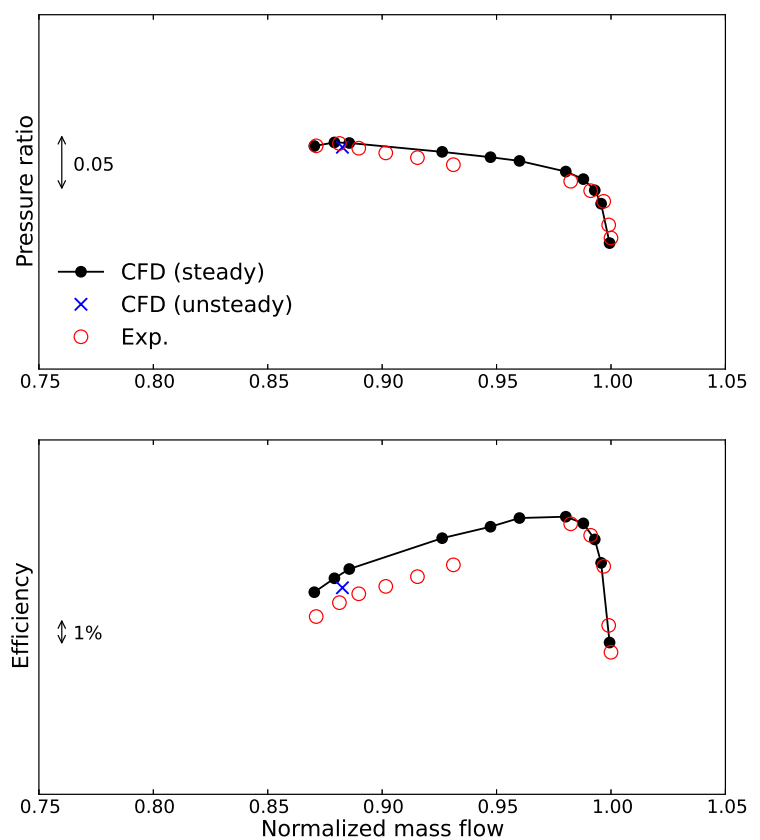

Fig. 6: Performance characteristics for FAN A, 100\% speed
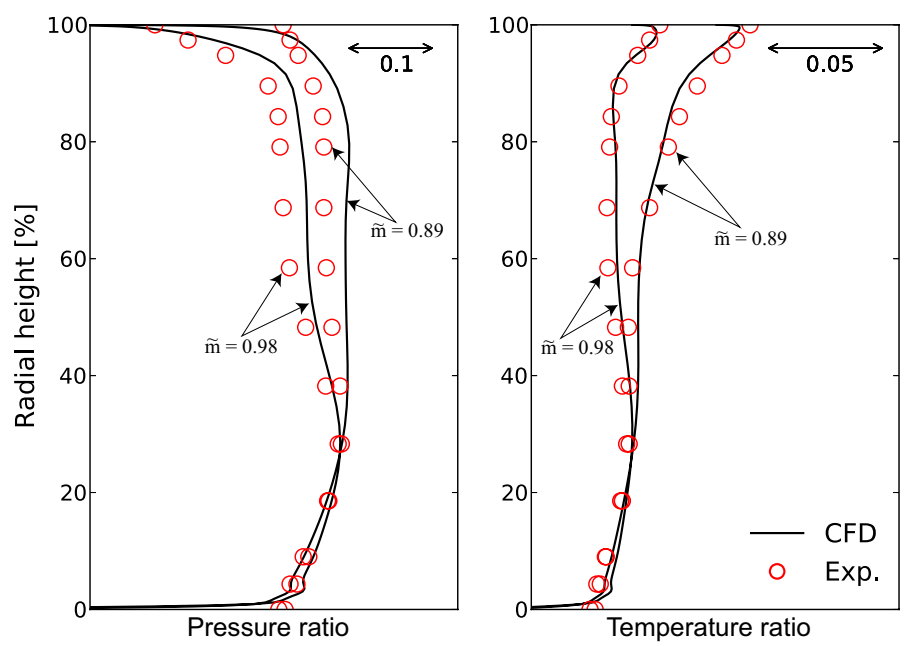

Fig. 7: Spanwise profiles for FAN A at inlet to the bypass duct, at peak efficiency and low flow rates reflected in the unsteady pressure transducer data, is well-captured in the computations.

The pressure traces at stall inception, from experiment and computation, for VITAL, are presented in Fig. 8. 15 rotor revolutions are shown. Initially, the signal corresponds to the 18 blades of the fan. Between times of 2 revs and 3 revs (in both experiment and computation) a spike-type disturbance emerges and grows rapidly, within 5 revolutions, into a fullydeveloped rotating stall cell. Figure 8 shows that the qualitative behaviour is captured in the computations and that the growth rate, initial speed of the disturbance, and final speed of the stall cell are also quantitatively reproduced. From the pressure traces, the final size of the stall cell is approximately 180 degrees and rotates at $55 \%$ of rotor speed ( $62 \%$ in the computation). The experimental data indicates the presence of more structure within the stall cell than is captured in the computations, as the cell grows between 5 revs and 10 revs, but the initial and final states (spike disturbance and mature stall cell), as well as 
the time taken to transition between the two, are well-captured in the computations.

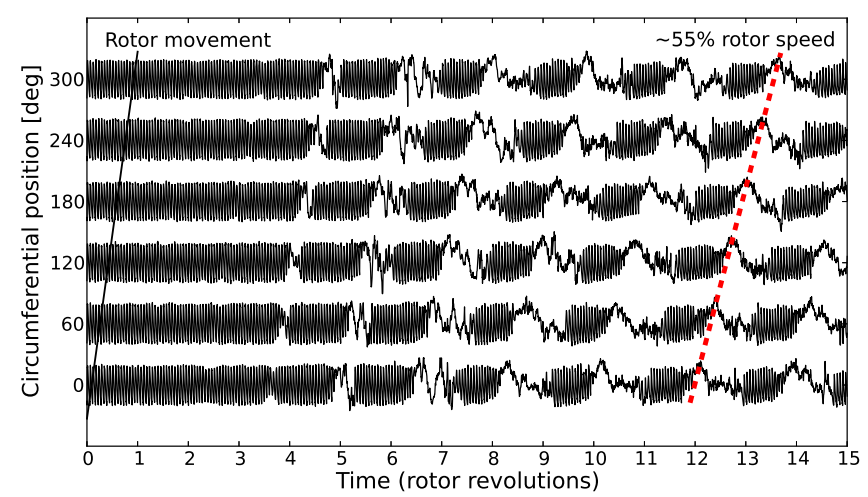

(a) Experiment

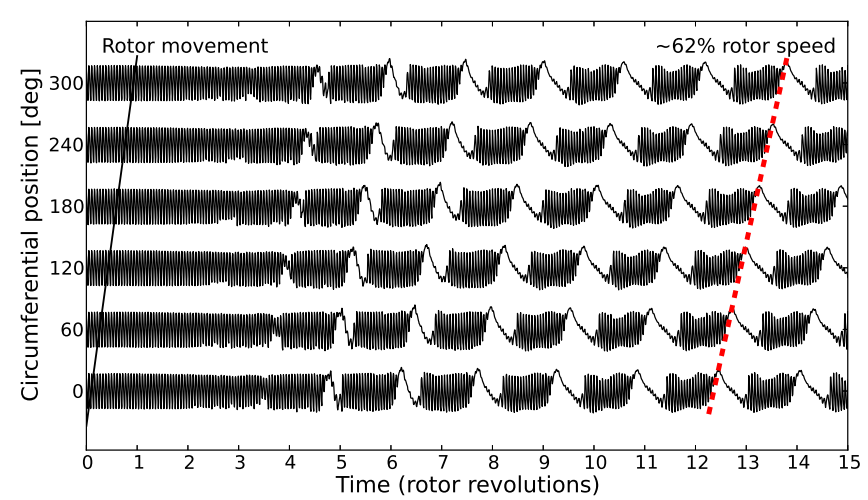

(b) Computation

Fig. 8: Measured and computed casing pressure traces at stall-inception, for VITAL

The contrasting behaviour of FAN A is illustrated in the pressure traces of Fig. 9. Again, the computations reproduce the behaviour closely: a disturbance emerges after 4 revs, reaching a final size approximately 5 revolutions later. The pressure transducer traces indicate a circumferential extent of approximately 60 degrees for the stall cell in FAN A, and, commensurate with its smaller circumferential extent compared to VITAL, a faster propagation speed of $87 \%$ of rotor speed $(83 \%$ in the computation).

The low hub-to-tip radius ratio of the fans means that the smaller circumferential size of the stall cell of FAN A is likely to be part-span, and that of VITAL full-span. This is confirmed by the computed rotor exit entropy contours of Fig. 10.

The blockage of the smaller part-span stall cell of FAN A, as compared to the full-span stall cell of VITAL, is responsible for a commensurately smaller drop in fan pressure ratio during the 15 revolutions shown in Figs. 8 and 9 . The instantaneous pressure ratio, extracted once per revolution, is shown in Fig. 11.

The full annulus unsteady computations have reproduced the markedly different stall behaviour of VITAL and FAN A. As well as the differing size of the final rotating stall cell, we will show in the next section that each fan has a different mechanism at the origin of the stall inception process. 


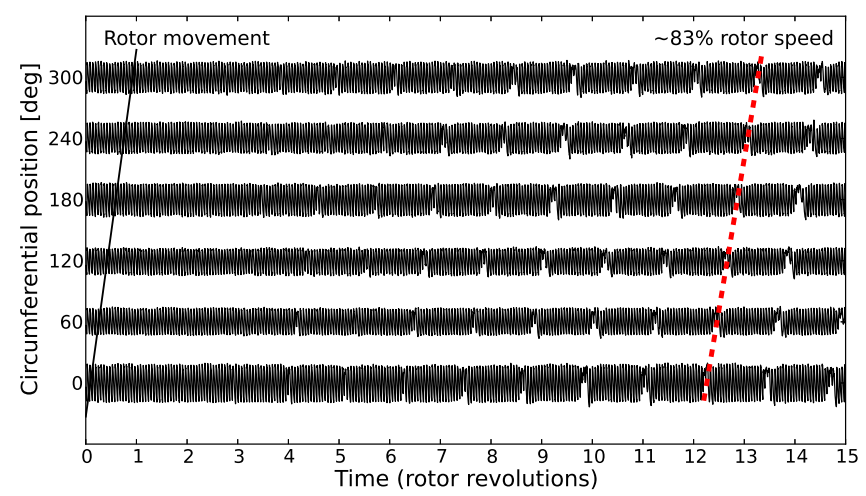

(a) Experiment

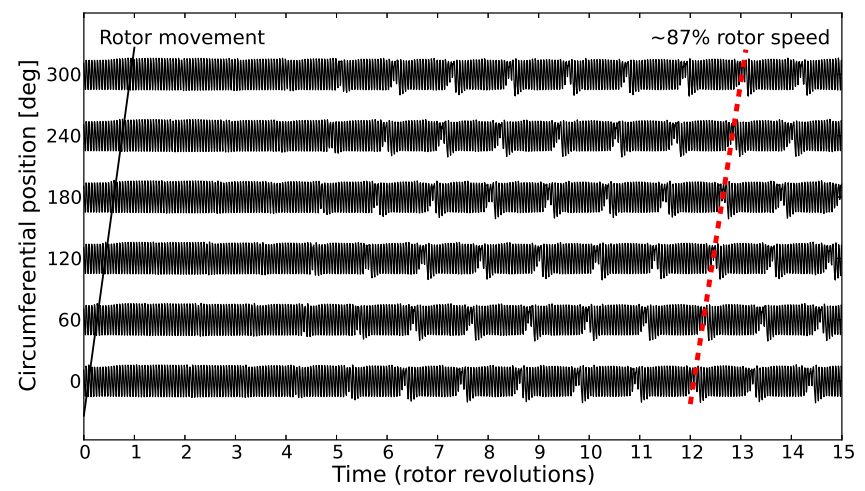

(b) Computation

Fig. 9: Measured and computed casing pressure traces at stall-inception, for FAN A

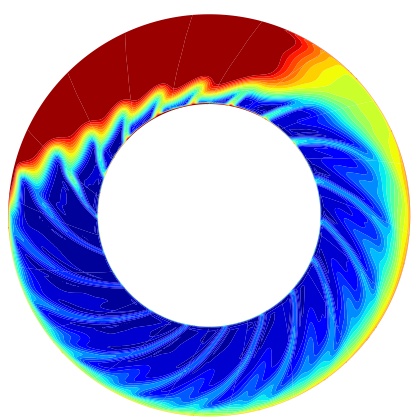

(a) VITAL

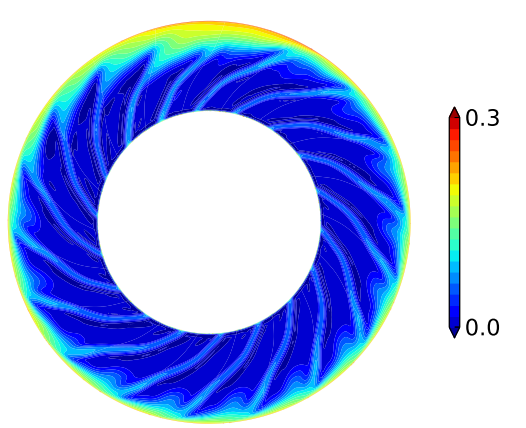

(b) FAN A

Fig. 10: Computed fan outlet entropy during fully-developed rotating stall

\section{STALL INCEPTION MECHANISMS}

Radial vorticity in the tip region has been found to be a useful marker for the flow mechanisms present at stall inception. In Fig. 12, we show radial vorticity, and pressure coefficient, at $99.5 \%$ span, for three instances in time corresponding to the VITAL computation of Fig. 8(b). Before stall, the tip leakage flow is tangential and has begun to impinge on the leading edge of the adjacent blade. During stall inception (at $t=4$ revs), the tip leakage flow spills ahead of the leading edge; this causes the leading edge separation seen at time $t=6.5$ revs. During this process, the casing pressure field, as would be recorded by the pressure transducers upstream of the fan, changes from a regular repeating pattern $(t=1 \mathrm{rev})$, to a localised disturbance $(t=4$ revs $)$ and then to a full stall cell $(t=6.5$ revs $)$. 


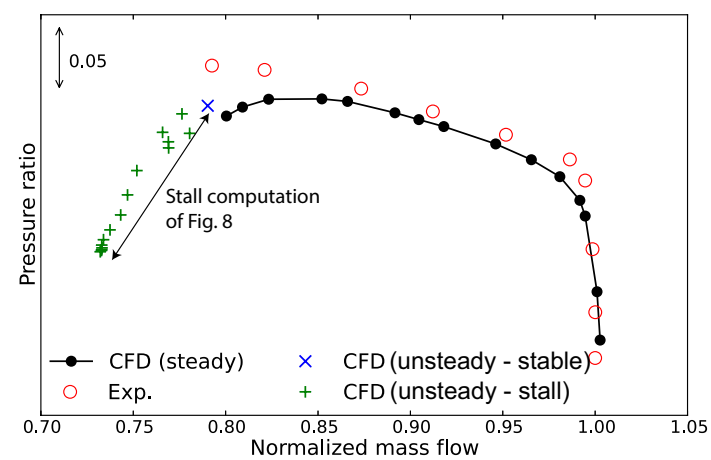

(a) VITAL

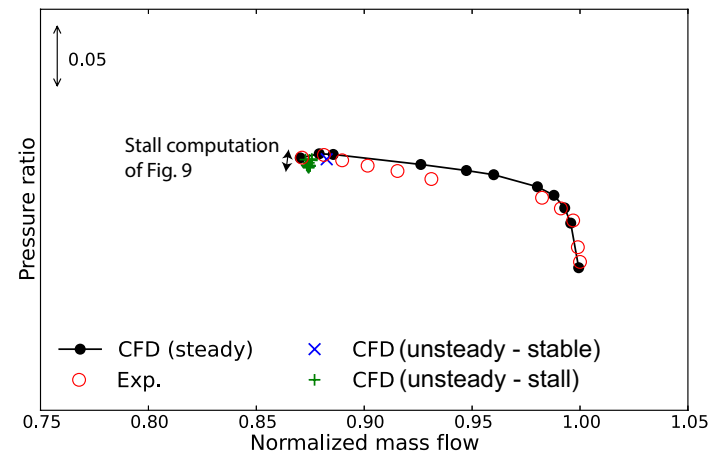

(b) FAN A

Fig. 11: Computed pressure ratio characteristics (one point per rev) during the stall inception computations of Figs. 8 and 9

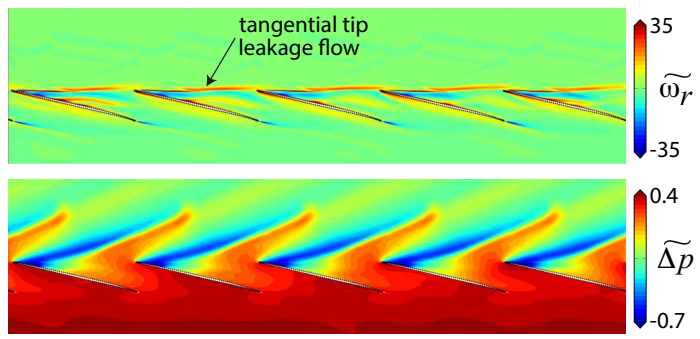

(a) $t=1$ rev - stable operation

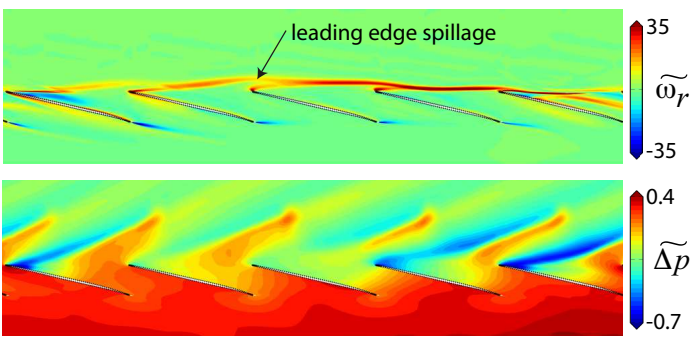

(b) $t=4$ revs - stall inception
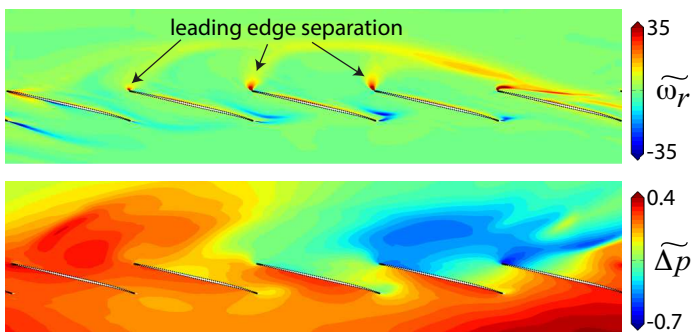

(c) $t=6.5$ revs - fully developed stall cell

Fig. 12: Computed radial vorticity $\widetilde{\omega_{r}}$ and static pressure $\widetilde{\Delta p}$ at $99.5 \%$ span during the stall of VITAL 


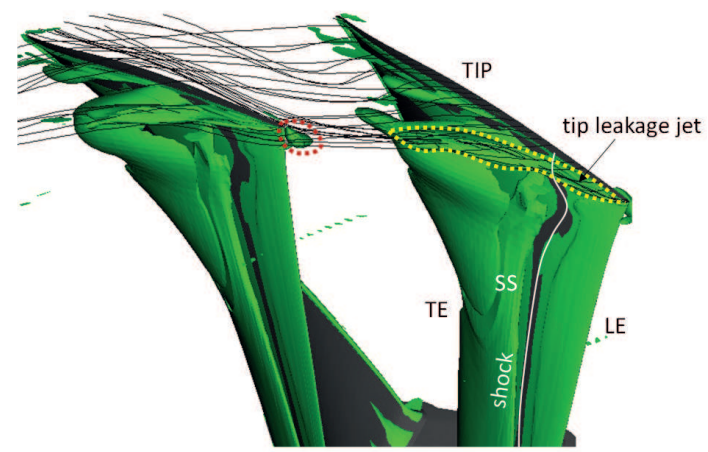

(a) $\mathrm{t}=1 \mathrm{rev}$

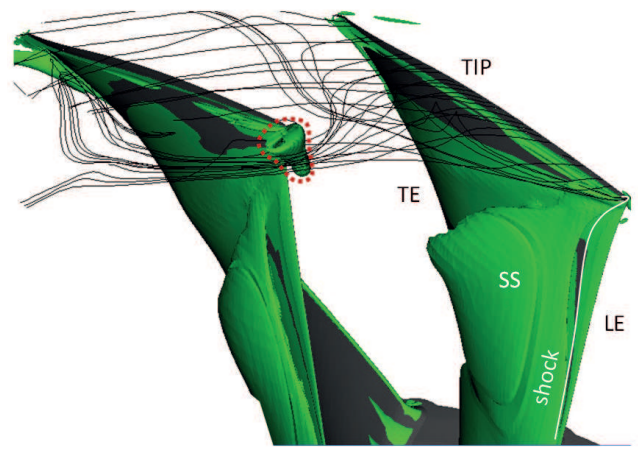

(b) $\mathrm{t}=4$ revs

Fig. 13: Iso-surface of the vortex detection 'Q' criterion, and instantaneous streamlines, during stall of VITAL

The high aspect ratio of the fan blades means that the spanwise extent of the perturbations of Fig. 8 is uncertain from the pressure transducer data alone. In Fig. 13 (at the first two time instants of Fig. 12), we present iso-surfaces of the ' $Q$ ' vortex criterion as well as instantaneous streamlines in the tip leakage flow. Prior to stall, the leakage flow is impinging on the leading edge of the adjacent blade. The $Q$ criterion iso-surface also indicates the presence of a suction-surface separation, inboard of the tip, that extends towards mid-span. As the tip leakage flow spills ahead of the leading edge, Fig. 13(b), vorticity is shed in the established mechanism for spike generation. The presence of the suction-surface separation further down the span, due to the peak pressure rise for VITAL being in the $60 \%$ to $70 \%$ span region, allows the stall cell to grow rapidly into the full-span stall cell shown in Fig. 10(a).

The corresponding radial vorticity and static pressure plot for FAN A is given in Fig. 14. The tip leakage flow trajectory is not tangential at $t=1 \mathrm{rev}$ and does not spill forwards of the leading edge plane during the subsequent stall inception. Instead, the change between the snapshots at $t=1 \mathrm{rev}$ and $t=4 \mathrm{revs}$ is the growth in the size of the corner separation. The pressure coefficient plot shows that this separation is induced by the shock. At the throttle position for which the computation was performed, the radial vorticity contours during fully-developed (part-span) stall indicate that the flow separates just aft of the leading edge (at approximately $10 \%$ chord) and the cell propagates by the rotating blockage process described by Emmons et al. [17].

The pressure contours of Fig. 14, in accord with the upstream pressure traces of Fig. 9, show that even the fully developed stall cell causes comparatively little disruption to the pressure field. Correspondingly, the $Q$ criterion iso-surface of Fig. 15 illustrates that the separation, downstream of the shock, is confined to the outer $10 \%$ of span. Relative to VITAL, the increased tip loading, as compared to the mid-span of the blade, of FAN A means that the flow remains attached over the bulk of the 


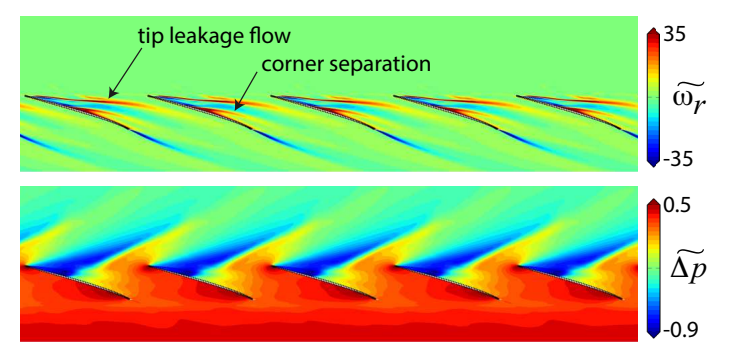

(a) $t=1$ rev - stable operation
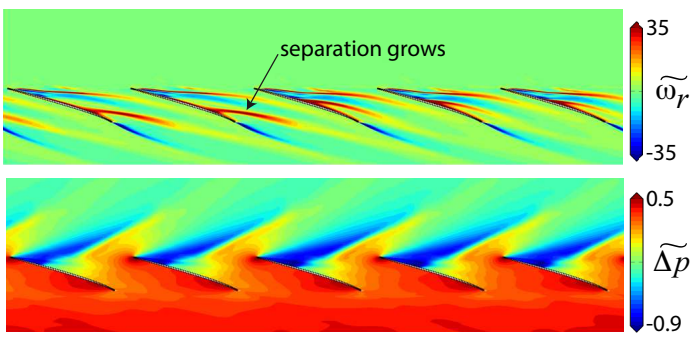

(b) $\mathrm{t}=4$ revs - stall inception
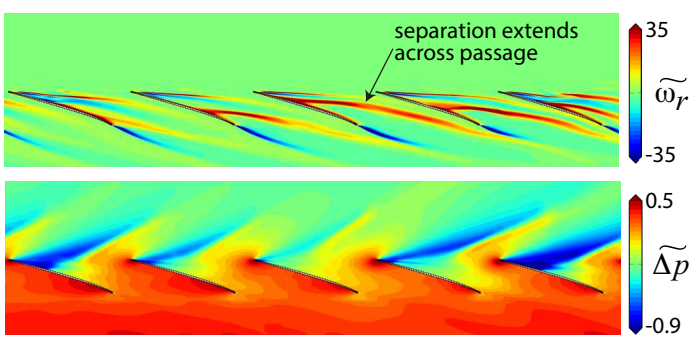

(c) $t=6.5$ revs - fully developed stall cell

Fig. 14: Computed radial vorticity $\widetilde{\omega_{r}}$ and static pressure $\widetilde{\Delta p}$ at $99.5 \%$ span during the stall of FAN A

span and a part-span cell forms, Fig. 10(b). During the experimental test of FAN A, the throttle was opened once the fan entered part-span stall.

\section{FAN DESIGN AND STALL INCEPTION}

The two fan designs, VITAL and FAN A, initiate stall inception via different mechanisms (tip leakage spillage upstream of the leading edge, and corner separation blockage) and have different mature rotating stall cell behaviour (full-span, and part-span). We now discuss the connections between the fan aerodynamic design and the resultant behaviour at stall.

For both fans, stall inception occurs at the tip. The pressure distributions at $99.5 \%$ span, at the start of the time period shown in the casing pressure trace data of Figs. 8 and 9, are shown in Fig. 16. The high leading edge loading shows the positive incidence of both tip sections at this operating point, and the larger enclosed area of the FAN A distribution reflects the increased tip loading of this blade. An important parameter in determining whether the tip leakage spillage or corner separation blockage mechanism promotes spike-type stall inception is the axial momentum flux of the tip leakage flow [5]. The axial momentum flux of the tip leakage flow, per unit axial chord, non-dimensionalised by the total inlet axial momentum flux, is given by, 


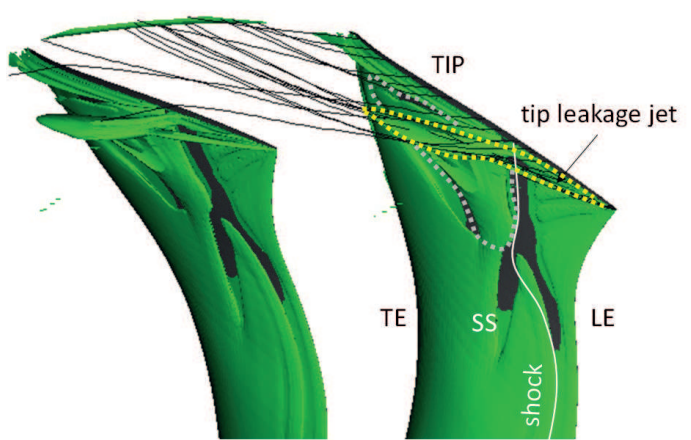

(a) $\mathrm{t}=1 \mathrm{rev}$

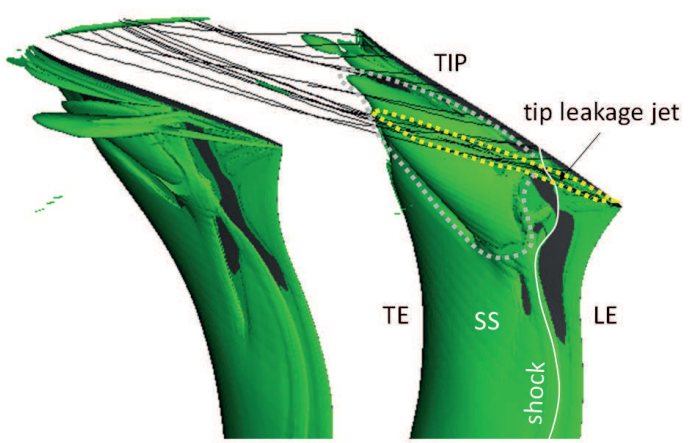

(b) $\mathrm{t}=4$ revs

Fig. 15: Iso-surface of the vortex detection 'Q' criterion, and instantaneous streamlines, during stall of FAN A

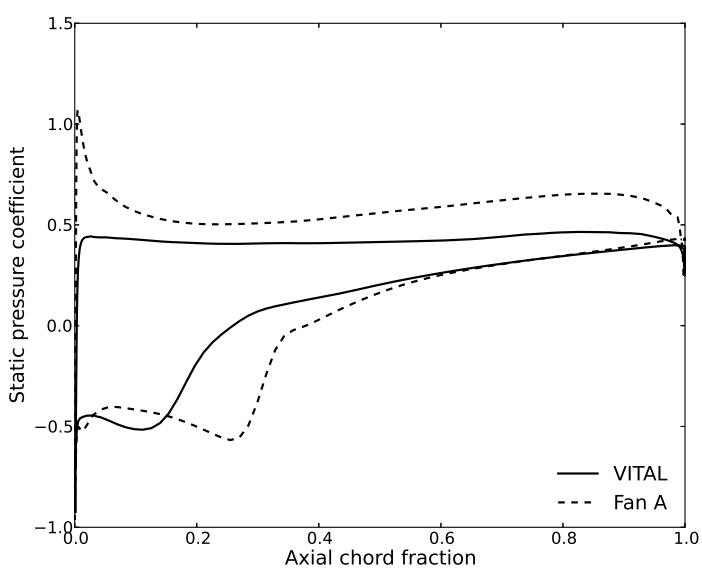

Fig. 16: Computed pressure distribution at $99.5 \%$ span, at $t=0$ revs in Figs. 8 and $9, C_{p}=\frac{p-p_{1}}{\frac{1}{2} \rho W_{1}^{2}}$

$$
\mu=\int_{\text {gap }} \frac{\rho V_{n} V_{x} c_{x}}{\dot{m}_{\text {in }} V_{x i n} \cos \alpha} d r
$$

where $V_{n}$ and $V_{x}$ are the components of leakage flow velocity normal to the camberline and in the axial direction respectively, and $\alpha$ is the slope of the camberline to the axial direction. The chordwise distribution of $\mu$, for VITAL and FAN A, at the same operating point as Fig. 16, is shown in Fig. 17. The pressure difference across the blade tip is greatest over the first 20\% of chord for both fans and this is where the axial momentum flux magnitude is largest. However, despite the similar pressure difference shown in Fig. 16, VITAL has twice the peak axial momentum flux of FAN A. Hewkin-Smith et al. [5] identified 
the linkage between axial momentum flux magnitude over the forward part of the blade and the spillage of tip leakage flow upstream of the leading edge plane (as illustrated, for VITAL, in Fig. 12).

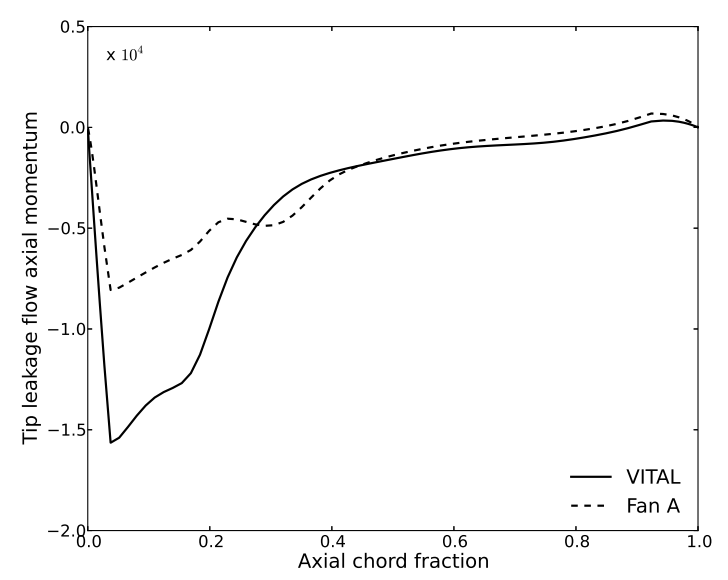

Fig. 17: Normalized tip leakage axial momentum flux, $\mu$

At the tip, VITAL has a higher stagger, and a higher solidity, as compared to FAN A, sketched in Fig. 18. The leakage flow is shown leaving the tip gap only over a fraction $f$ of the chord. The total axial momentum flux leaving the gap, non-dimensionalised by the axial momentum entering the passage is then given by,

$$
\mu_{\mathrm{tot}}=\frac{\dot{m}_{L} V_{x L}}{\dot{m}_{\mathrm{in}} V_{x \mathrm{in}}}=\frac{\rho_{L} V_{n} f c t V_{x L}}{\rho_{\mathrm{in}} V_{x \mathrm{in}}^{2} s h}
$$

where the leakage jet axial velocity is $V_{x L}$, the tip clearance is $t$, the pitch $s$ and the blade span $h$. The increased solidity $c / s$ of VITAL therefore results in an increase of $\mu_{\text {tot }}$. If the flow exits the gap perpendicularly to the chord $\left(V_{x L}=-V_{n} \sin \gamma\right.$, where $\gamma$ is the stagger angle) then the larger stagger angle of VITAL, compared to FAN A, will also increase $\mu_{\text {tot. }}$ The computations indicate (Figs. 12 and 14) that the leakage jet of VITAL is angled more toward the upstream axial direction than FAN A, further increasing $\mu_{\mathrm{tot}}$.

Equation (2) provides a qualitative connection between choices made by the fan designer (tip pressure distribution, stagger and solidity) and the stall inception behaviour of the fan.

\section{CONCLUSIONS}

The two transonic, low pressure ratio, fans studied in this paper exhibited different rotating stall behaviour when tested experimentally. Unsteady computations, in agreement with the measurement data, have been used to identify the mechanisms that precipitate the spike-type stall inception, and the subsequent stall cell development, in each case.

From the combined experimental and computational investigation, we draw the following conclusions:

1. The two mechanisms that are at the origin of spike-type stall inception in the fans studies are: spillage of the tip leakage flow forward of the leading edge plane (VITAL); sudden growth of tip corner separation blockage (FAN A). These mechanisms are in accord with the findings in core compressors. 


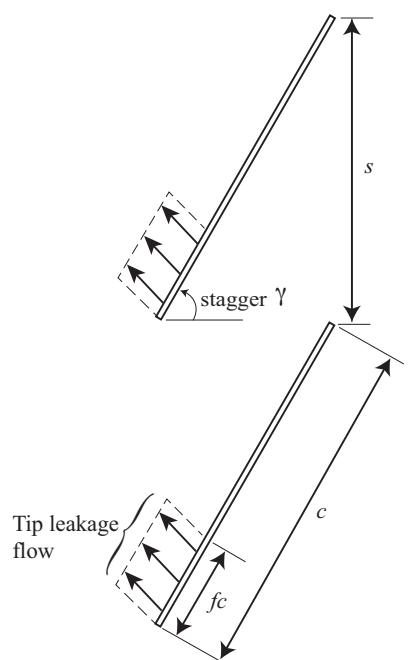

(a) VITAL
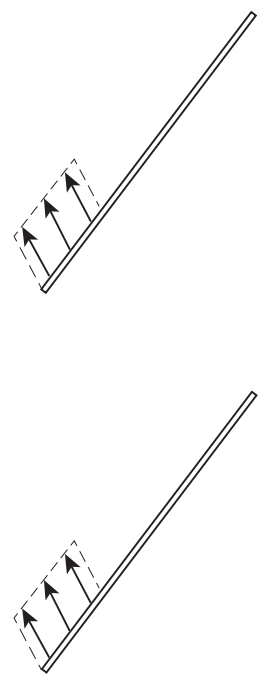

(b) FAN A

Fig. 18: Schematic of the tip leakage jet of VITAL and FAN A, showing the reduced stagger and solidity of FAN A

2. The transonic flow that characterises fan aerodynamics means that the blockage growth at stall of FAN A is driven by shock-boundary layer interaction.

3. The greater magnitude of axial momentum flux of the tip clearance flow of VITAL, compared to FAN A, is consistent with the leading edge spillage mechanism of VITAL. A simple model links the fan design parameters of tip loading, tip stagger and tip solidity, to the tip clearance axial momentum flux. The increased solidity and tip stagger of VITAL leads to a higher axial momentum flux magnitude, at the same tip loading, and hence to the leading edge spillage of the tip clearance flow.

4. The low hub-to-tip radius ratio of the fan blade means that the growth of the the stall cell is influenced by the loading of the blade away from the tip. In VITAL, the loading toward mid-span is higher than at the tip section (a suction-surface separation, inboard of the tip, is present prior to stall inception), so that the instability of the tip rapidly leads to a fullspan stall cell. In FAN A, the spanwise loading distribution is more uniform so that the flow over the bulk of the blade remains stable (part-span stall) even after the appearance of a spike at the tip.

\section{Acknowledgements}

The authors gratefully acknowledge Innovate UK for funding this work via the UK Aerospace Technology Institute, and Rolls-Royce plc for permission to publish.

\section{APPENDIX}

In this section, representative examples of the effect of changing from the baseline Spalart-Allmaras model, to the model with 'helicity correction' [15] are provided. During comparisons with the measurement data, obtaining the required spanwise profiles of pressure ratio and temperature ratio, in the outer $30 \%$ of span, was found to be sensitive to the turbulent eddy viscosity in this region. Specifically, increasing the turbulent production term was found to improve these spanwise profiles and extend the predicted range of stable operation. At first this was done by manually scaling the production term in the outer 
$10 \%$ of span, but, following [13], similar improvements were obtained using the helicity correction to the Spalart-Allmaras model without having to define a zone for increased turbulence production a priori.

Figure 19 shows the pressure ratio and efficiency characteristics for VITAL with the original and modified turbulence models. The range is extended by 0.06 of normalized mass flow, although the deviation from the measured data at mass flows below the stable steady computations with the original Spalart-Allmaras model, is increased. Figure 20 shows that the increased eddy viscosity acts to reduce the size of three-dimensional separations with the effect of reducing the radially outwards flow in both the hub region and also downstream of the shock in the outer half of the span.
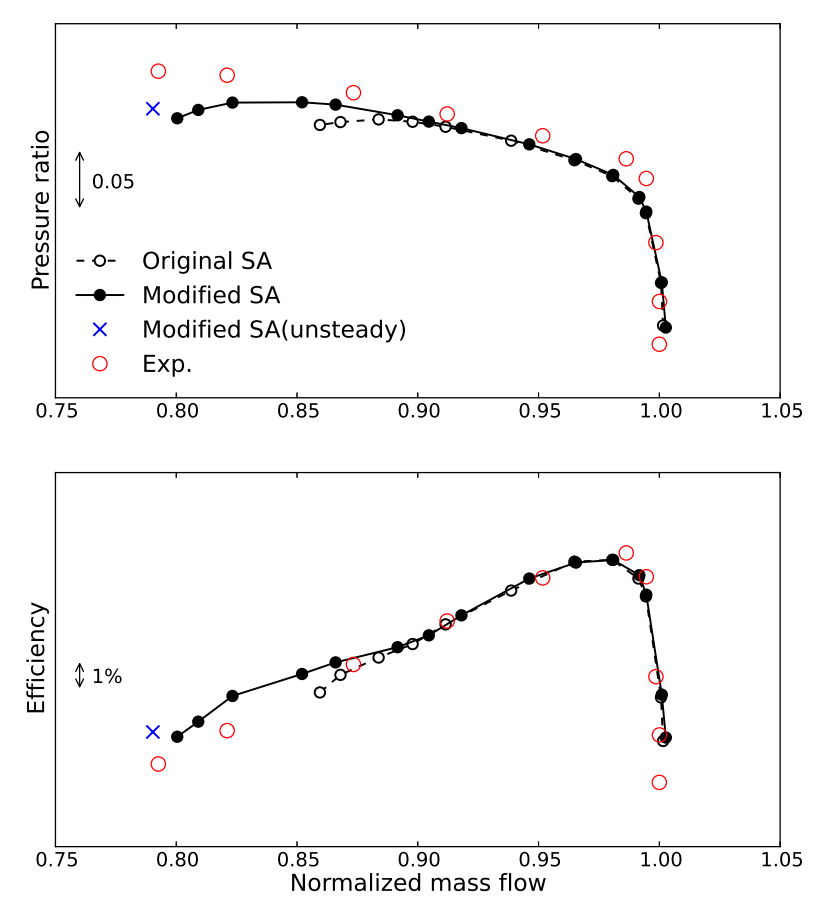

Fig. 19: Performance characteristics for VITAL , 100\% speed, with original and modified Spalart-Allmaras model

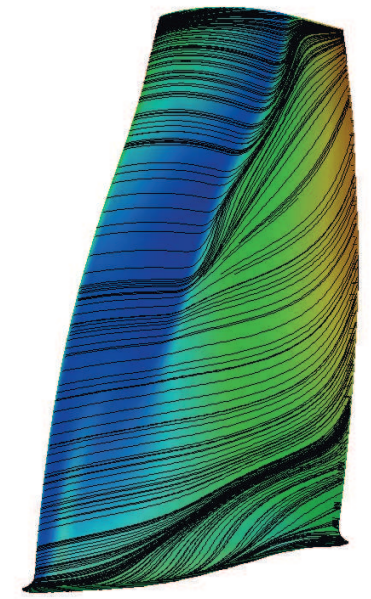

(a) Modified SA model

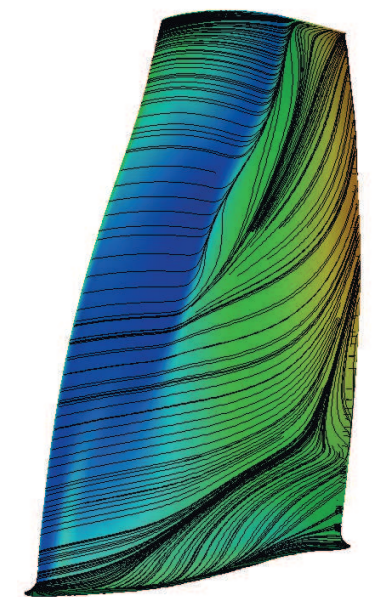

(b) Original SA model

Fig. 20: VITAL suction-surface streamlines at peak efficiency, with original and modified Spalart-Allmaras model 


\section{NOMENCLATURE}

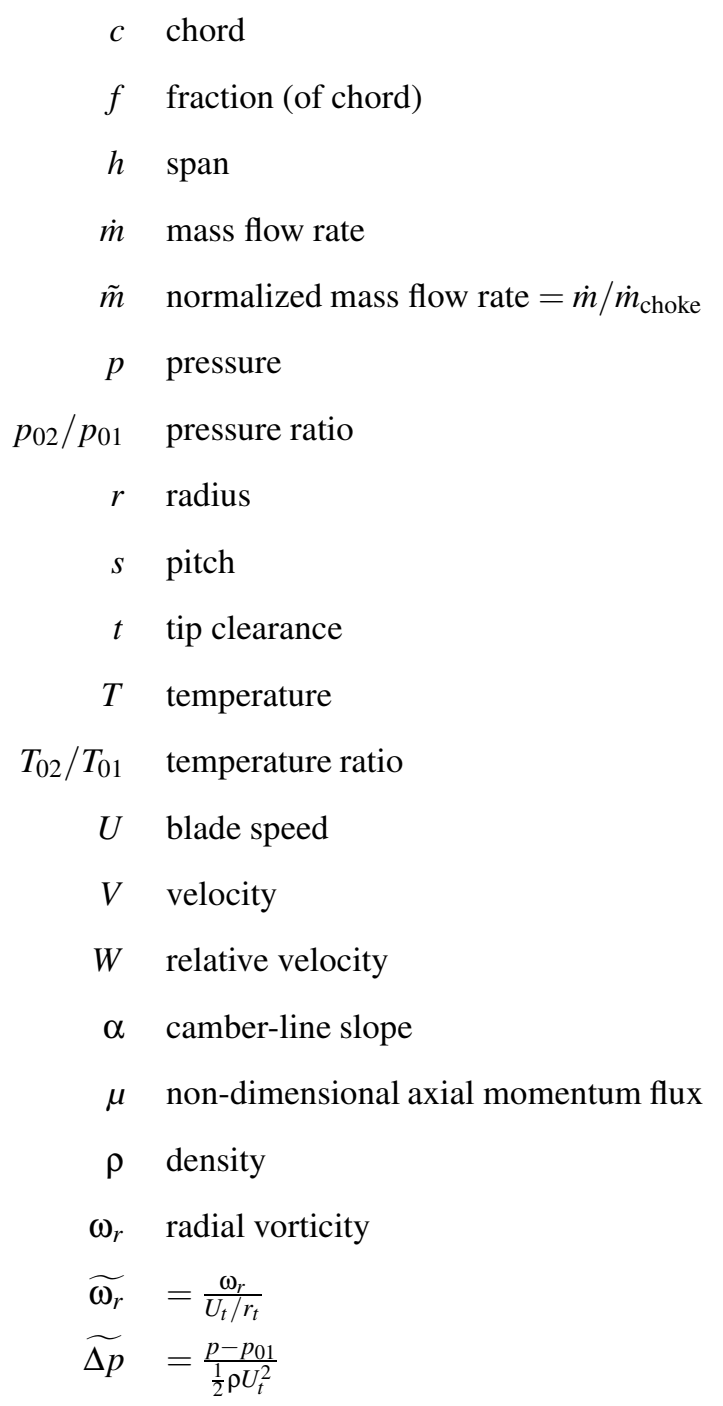

subscripts:

0 stagnation

1 , in inlet

2 outlet

$t$ tip

$L \quad$ leakage

$n$ normal (to suction-surface)

$x$ axial

\section{References}

[1] Camp, T., and Day, I., 1998. "A study of spike and modal stall phenomena in a low-speed axial compressor". ASME J. Turbomach., 120, pp. 393-401.

[2] Garnier, V., Epstein, A., and Greitzer, E., 1991. "Rotating waves as a stall inception indication in axial compressors". 
ASME J. Turbomach., 113, pp. 290-302.

[3] Tan, C., Day, I., Morris, S., and Wadia, A., 2010. "Spike-type compressor stall inception, detection and control”. Ann. Rev. Fluid Mech., 42, pp. 275-300.

[4] Pullan, G., Young, A., Day, I., Greitzer, E., and Spakovszky, Z., 2015. “Origins and structure of spike-type rotating stall”. ASME J. Turbomach., 137(5), 051007.

[5] Hewkin-Smith, M., Pullan, G., Grimshaw, S., Greitzer, E., and Spakovszky, Z., 2017. "The role of tip leakage flow in spike-type rotating stall inception”. ASME IGTI Turbo Expo, GT2017-63655.

[6] Strazisar, A., 1985. "Investigation of flow phenomena in a transonic fan rotor using laser anemometry". ASME J. Eng. Gas Turbines Power, 107(2), pp. 427-435.

[7] Copenhaver, W., Puterbaugh, S., and Hah, C., 1997. "Unsteady flow and shock motion in a transonic compressor rotor". AIAA J. Propulsion Power, 13(1), pp.17-23.

[8] Adamczyk, J., Celestina, M., and Greitzer, E., 1993. "The role of tip clearance in high-speed fan stall". ASME J. Turbomach., 115 , pp. 28-38.

[9] Hah, C., Bergner, J., and Schiffer, H., 2006. "Short length scale rotating stall inception in a transonic axial compressor: Criteria and mechanisms". ASME IGTI Turbo Expo, GT2006-90045.

[10] Choi, M., Smith, N., and Vahdati, M., 2012. "Validation of numerical simulation for rotating stall in a transonic fan". ASME J. Turbomach., 135(2), 021004.

[11] Korsia, J., 2009. "Vital european research and development programme for greener aero-engines". ISABE 2009-1114.

[12] Gunn, E., and Hall, C., 2014. “Aerodynamics of boundary layer ingesting fans”. ASME IGTI Turbo Expo, GT201426142.

[13] Lee, K., Wilson, M., and Vahdati, M., 2017. "Validation of a numerical model for predicting stalled flows in a low-speed fan”. ASME IGTI Turbo Expo, GT2017-63245.

[14] Brandvik, T., and Pullan, G., 2011. “An accelerated 3d navier-stokes solver for flows in turbomachines”. ASME J. Turbomach., 133, 021025.

[15] Liu, Y., Lu, L., Fang, L., and Gao, F., 2011. "Modification of spalart-allmaras model with consideration of tubulence energy backscatter using velocity helicity”. Phys. Lett. A, 375(24).

[16] Vahdati, M., Sayma, A., Freeman, C., and Imregun, M., 2005. "On the use of atmospheric boundary conditions for axial-flow compressor stall simulations". ASME J. Turbomach., 127, pp. 349-351.

[17] Emmons, H., Pearson, C., and Grant, H., 1955. “Compressor surge and stall propagation”. Trans. ASME, 79, pp. 455-469. 